\title{
OJS

\section{O ENSINO DE CLIMATOLOGIA NA GEOGRAFIA ESCOLAR: O JOGO COMO POSSIBILIDADE PEDAGÓGICA}

\author{
Yan Castro Lisboa ${ }^{1}$, Cláudia Aresi $^{2}$, Carina Copatti ${ }^{3}$ \\ ${ }^{1}$ Graduado em Geografia (L) - Universidade de Passo Fundo (UPF).E-mail: y-ancl@hotmail.com - ORCID Id: \\ https://orcid.org/0000-0003-1996-0899 \\ ${ }^{2}$ Mestra em Geografia. Docente no curso de Geografia (L) da Universidade de Passo Fundo (UPF). E-mail: \\ claudiaaresi@upf.br-ORCID Id: https://orcid.org/0000-0002-6126-892X \\ ${ }^{3}$ Doutora em Educação nas Ciências - Universidade Regional do Noroeste do Estado do Rio Grande do Sul \\ (UNIJUI).E-mail: c.copatti@hotmail.com_ORCID Id: https://orcid.org/0000-0003-0485-388X
}

Artigo recebido em 08/06/2020 e aceito em 14/07/2020

\begin{abstract}
RESUMO
Pensar sobre a aprendizagem na Geografia constitui-se como um desafio e uma necessidade entre professores formadores e acadêmicos em formação para a docência, isso, pois, para melhorar o ensino escolar e contribuir de modo efetivo para a educação geográfica se faz necessário mobilizar conhecimentos e construir estratégias metodológicas. Portanto, no presente artigo, objetivamos descrever possibilidades de construção do conhecimento de climatologia a partir do uso de jogos pedagógicos no ensino escolar de geografia, tecendo relação entre os aspectos teórico-metodológicos e a atividade prática, visando contribuir à educação geográfica dos alunos do Ensino Médio. Nesse sentido, é relevante responder a seguinte questão: de que modo, a partir do jogo pedagógico, pode-se contribuir à aprendizagem de climatologia na Geografia Escolar? Utilizam-se aportes de referenciais teóricos do campo da educação, ensino de geografia e climatologia, e a pesquisa-ação, a partir de uma oficina pedagógica desenvolvida com alunos do Ensino Médio noturno. Salienta-se a importância da relação entre os conhecimentos a serem construídos com eles e suas participações ativas na aprendizagem, valorizando o trabalho em equipe, a comunicação e as relações com a realidade local em diálogo com outras escalas geográficas. Isso possibilita melhores resultados no processo de aprendizagem na disciplina de Geografia.
\end{abstract}

Palavras-Chave: Ensino de climatologia; Jogo pedagógico; Ensino de Geografia; Processo de aprendizagem.

\section{THE TEACHING OF CLIMATOLOGY IN SCHOOL GEOGRAPHY: THE GAME AS A PEDAGOGICAL POSSIBILITY}

\begin{abstract}
Thinking about learning in geography constitutes a challenge and a need among teacher's trainers and academics in training for teaching, therefore, to improve school education and contribute effectively to geographic education it is necessary to mobilize knowledge and build methodological strategies. Therefore, in this article, we aim to describe possibilities of construction of knowledge of climatology from the use of pedagogical games in geography school education, weaving a relationship between theoretical and methodological aspects and practical activity, aiming to contribute to the geographical education of high school students. In this sense, it is relevant to answer the following question: how, from the pedagogical game, can one contribute to the learning of climatology in School Geography? Contributions of theoretical references in the field of education, geography teaching and climatology, and action research are used, from a pedagogical workshop developed with students of night high school. It emphasizes the importance of the relationship between the knowledge to be built with them and their active participation in learning, valuing teamwork, communication and relationships with the local reality in dialogue with other geographical scales. This enables better results in the learning process in the geography discipline.
\end{abstract}

KEYWORDS: Climatology teaching. Pedagogical practice. Geography Teaching. Learning process. 


\section{INTRODUÇÃO}

$\mathrm{O}$ ato de pensar o processo de ensino e aprendizagem, a prática pedagógica e o ensino de Geografia constituem-se como desafio aos professores formadores e acadêmicos em formação para a docência, no sentido de melhorar o ensino escolar e contribuir de modo efetivo para a educação geográfica. Sendo assim, relacionam-se aspectos da prática educativa e aportes teóricos essenciais à construção do conhecimento geográfico, originando este artigo, o qual apresenta reflexões a partir de uma atividade prática realizada com alunos do ensino médio, utilizando um jogo pedagógico como percurso de construção do conhecimento geográfico.

O objetivo do artigo é descrever possibilidades de construção do conhecimento de climatologia a partir do uso de jogos pedagógicos no ensino escolar de geografia, tecendo relação entre os aspectos teórico-metodológicos e a atividade prática, visando contribuir à educação geográfica dos alunos do Ensino Médio. Nesse sentido, é relevante responder a seguinte questão: de que modo, a partir do jogo pedagógico, pode-se contribuir à aprendizagem de climatologia na Geografia Escolar?

Referenciais bibliográficos da área de Geografia e Educação, como Callai (2005), Santos (1988), Mendonça e Oliveira (2007), Sawczuk e Moura (2012) fornecem aportes à construção das reflexões que se propõem ao ensino de geografia. As reflexões construídas com base nestes autores articulam-se com a pesquisa-ação e as atividades práticas com jogos pedagógicos.

Os jogos pedagógicos são importantes para o processo de aprendizagem dos alunos da Educação Básica, pois, ao aliar teoria e prática, utilizando diferentes metodologias, é possível construir distintas formas de ensino e proporcionar ao aluno a compreensão de temas e conceitos geográficos de modo mais significativo para o seu entendimento perante ao conteúdo. Para compreender essas possibilidades, compreendemos a necessidade de utilizar a pesquisaação como possibilidade metodológica de investigação em sala de aula, na relação professoraluno. Sobre a pesquisa-ação, Engel (2000, p. 182) descreve que:

\footnotetext{
A pesquisa-ação procura unir a pesquisa à ação ou prática, isto é, desenvolver o conhecimento e a compreensão como parte da prática. É, portanto, uma maneira de se fazer pesquisa em situações em que também se é uma pessoa da prática e se deseja melhorar a compreensão desta.
}

Tripp (2005, p. 445) considera que "a pesquisa-ação educacional é principalmente uma estratégia para o desenvolvimento de professores e pesquisadores de modo que eles possam 
utilizar suas pesquisas para aprimorar seu ensino e, em decorrência, o aprendizado de seus alunos". Nesse sentido, a interação do acadêmico com os alunos do Ensino Médio a partir do planejamento da oficina constitui a base das reflexões propostas.

A participação ativa do acadêmico no planejamento, na execução e na realização da atividade prática contribui para ampliar essas propostas de práticas na Educação Básica, as quais são debatidas no artigo a partir da seguinte organização: a) Jogos pedagógicos nas aulas de Geografia: possibilidades para ensinar climatologia, relativo aos conceitos considerados basilares, a partir de referenciais teóricos que contribuem para o ensino de climatologia e uso de jogos pedagógicos; b) O "jogo das quatro pistas climáticas” no ensino médio, no qual se descreve o planejamento e a confecção do material para o jogo; c) O desenvolvimento do "jogo das quatro pistas climáticas", considerando as aprendizagens a partir dessa metodologia no Ensino Médio.

\section{JOGOS PEDAGÓgICOS NAS AULAS DE GEOGRAFIA: POSSIBILIDADES PARA ENSINAR CLIMATOLOGIA}

Ao construir propostas de atividades práticas para o Ensino de Geografia na Educação Básica, é importante considerar os conceitos e conteúdos a serem trabalhados em cada nível de aprendizagem. Isso envolve o conhecimento específico dessa área - a Geografia - seus conceitos e categorias de análise, que são essenciais para a leitura geográfica de aspectos que envolvem, neste caso, o ensino de climatologia. Nesse sentido, entender de climatologia não envolve apenas aspectos físicos e naturais, mas a relação que o ser humano constrói no espaço influenciado e influenciando nas dinâmicas do tempo atmosférico, do clima e outros elementos que interferem nestas relações.

Ao abordar esta área de conhecimento estudada na Geografia Escolar, Mendonça e Oliveira (2007), esclarecem que a Climatologia trata dos padrões de comportamento da atmosfera em suas interações com as atividades humanas e com a superfície terrestre no decorrer de um período de tempo muito longo. Conforme explica Dantas (2016), a climatologia como conteúdo da disciplina de Geografia traz consigo diversas situações que podem ser abordadas em sala de aula. Por exemplo, o quanto o clima interfere no modo de vestir das pessoas, permitindo uma percepção da importância da abordagem climatológica para o entendimento da relação sociedade-natureza. Mas não apenas isso, há uma série de situações, 
fenômenos e acontecimentos que decorrem das dinâmicas climáticas e que se relacionam com a vida humana em distintos lugares e regiões do planeta.

Ensinar Geografia requer que a abordagem dos conteúdos considere que os seres humanos e a natureza interagem entre si, e essas relações precisam ser interpretadas a partir de um conjunto de conceitos e temas que se relacionem com os lugares, com o cotidiano da vida humana, visto que é no cotidiano das pessoas que essas relações ganham significado. De acordo com Callai (2005, p. 234-235), “é no cotidiano da própria vivência que as coisas vão acontecendo e, assim, configurando o espaço, dando feição ao lugar”. Este se constrói e se configura de acordo com as relações que os sujeitos nele e a partir da relação com ele, estabelecem. Parte-se, portanto, do conceito de lugar para pensar sobre as condições do clima, suas dinâmicas e compreender suas características e distinções em outras realidades do país e do mundo, não considerando apenas o lugar em que vive o aluno.

Além disso, a paisagem é um conceito basilar para os estudos da Geografia, pois ao estudar temas como os climas do país, é a partir das paisagens que podemos relacioná-lo com as condições presentes em cada lugar. Isso porque, conforme Milton Santos (1988, p. 21), “[...] tudo aquilo que nós vemos, o que nossa visão alcança, é a paisagem. Esta pode ser definida como o domínio do visível, aquilo que a vista abarca. Não é formada apenas de volumes, mas também de cores, movimentos, odores, sons etc.”. Nesse sentido, a paisagem se transforma de acordo com a utilização do espaço pelos seres humanos a partir daquilo que constroem, do que modificam e das relações que estabelecem.

Sendo assim, a proposta de prática sempre precisa considerar os aportes teóricos com os quais se relaciona para fundamentar a construção de conhecimentos que se propõe. Além destes, os aportes metodológicos são essenciais para construir os processos pelos quais iremos ensinar determinado conteúdo. Portanto, é preciso ressaltar que ao escolher o recurso de que utilizaremos, precisamos relacionar teoria e prática, pois é dessa forma que vamos além de interpretações de senso comum, utilizando conhecimentos construídos pelo campo da ciência para refletir sobre situações que ocorrem no cotidiano, tornando o conhecimento geográfico algo mais acessível à compreensão dos alunos e mais significativo às suas vivências cotidianas.

No que consiste à importância dos jogos pedagógicos em sala de aula na Educação Básica, Sawczuk e Moura (2012, p. 2) ressaltam que:

A atividade com jogos rompe com as práticas tradicionais mantidas pelos professores, tirando o aluno da acomodação para a assimilação, dando a oportunidade de aprimorar a sua capacidade cognitiva, construindo um raciocínio lógico, tornando o processo de 
aprendizagem mais significativo. Com a participação do aluno na confecção do material, a visualização e o contato com o mesmo proporcionarão o desenvolvimento com o trabalho em grupo, a maturidade intelectual, a concentração, o respeito e as noções de espaço geográfico, entendendo o que se passa no mundo, relacionando situações do cotidiano com a realidade.

Ainda falando sobre os jogos, os autores Sawczuk e Moura (2012, p. 4) descrevem que "a introdução do lúdico nas aulas de Geografia proporciona ao aluno a assimilação de conteúdos de forma divertida, sem ter a preocupação momentânea de ser avaliado. As atividades lúdicas despertam o interesse dos alunos pelas aulas”. Ou seja, o Ensino de Geografia tem várias dimensões de estudos e diferentes conteúdos, dependendo da faixa etária de cada aluno, em determinadas séries dos Anos Finais do Ensino Fundamental e do Ensino Médio. Alguns desses conteúdos podem se tornar complexos no entendimento desses alunos e a possibilidade de criar um jogo pedagógico, não apenas leva ao objetivo de entretenimento, mas principalmente, de construção da aprendizagem de forma mais acessível e prática (LISBOA; JORGE, 2017).

Portanto, "as estratégias de ensino como as atividades lúdicas [...] desenvolvem no estudante habilidades de observação, cooperação (trabalho em equipe), a sociabilidade (discussão/diálogo), apropriação e construção do conhecimento" (TOPOLSKI et. al., 2018 p. 616). Da mesma forma, Lisboa e Jorge (2017, p. 125-126) caracterizam que essas atividades facilitam

o ensino, dando ao professor da escola do ensino básico, subsídios para buscar novos meios práticos na sua metodologia, visando oportunizar uma melhor aprendizagem do conteúdo, podendo ser de forma simples, mas que não leve muito tempo, pois os períodos de Geografia são diminutos no currículo escolar, no entanto deve possibilitar aos alunos a compreensão do tema proposto.

Assim, nota-se que o jogo pedagógico tem fundamental importância, demonstrando ser uma possibilidade de aprendizagem diferente em que, através de uma metodologia que oportuniza maior participação dos alunos, originando interação e o compartilhamento de conhecimentos. Essa metodologia, ao mesmo tempo em que auxilia na aprendizagem deles, também contribui para a construção de conhecimentos do acadêmico que está se constituindo como professor. Percebe-se, ainda, conforme Souza et. al. (2013, p. 2), que "o uso do jogo em sala de aula proporciona entusiasmo e motivação nos alunos, o que faz com que eles se interessem pelo conteúdo sem se tornar algo cansativo. Logo, os mesmos terão uma aprendizagem significativa". 
Seguindo essa mesma linha de pensamento, sobre os jogos em sala de aula e a ausência desta prática no uso de trabalhos pedagógicos pelos professores de Geografia, os mesmos autores descrevem que:

\begin{abstract}
Atualmente a sala de aula é vista pelos alunos e professores como algo desestimulador, são inúmeras as causas que levam a essa situação, pode-se citar que o problema mais "falado" é a indisciplina, porém, a falta de interesse muitas vezes está associada pelo fato de o conteúdo estar muito abstrato para eles, "sem nenhuma utilidade", com aulas sempre enfadonhas, tendo a Geografia como sinônimo de decoreba, sem influência com a sociedade e natureza (SOUZA et. al., 2013, p. 2).
\end{abstract}

Nesse momento, a percepção que se tem do Ensino de Geografia é a de construir junto ao aluno uma análise crítica da sua realidade, ou seja, através das explicações e dos conteúdos trabalhados pelo professor, o mesmo poderá se tornar capaz de fazer a relação destes com a sua realidade. Por isso a ideia de que a proposta de atividade prática planejada pelo professor, seja ele um profissional que está há muitos anos na escola, ou aquele que está em processo de formação, precisa sempre trazer aportes teóricos que auxiliem na construção do conhecimento, e se utilizem de metodologias que criem espaços para que o próprio aluno atue de modo participativo, construindo argumentações, desenvolvendo o raciocínio e dialogando com os colegas.

Isso irá orientá-lo para que possa criar uma consciência de responsabilidade perante o seu cotidiano, sua trajetória e sua vivência no dia a dia em qualquer local, tornando-se um cidadão capaz de mudanças significativas, com crítica social e consciente dos seus direitos perante a sociedade (NETO; BARBOSA, 2010). Ainda, capaz de interpretar as dinâmicas presentes no espaço, conseguindo operar os conceitos geográficos no seu cotidiano, seja para compreender aspectos do clima ou outras tantas temáticas de interesse que, na Geografia, são estudados.

Entendemos, portanto, que a utilização dos jogos são fundamentais para uma satisfatória construção do conhecimento geográfico pelos alunos do Ensino Médio, tendo em vista que os jogos são pensados e organizados para essa faixa etária. Para além disso, planejados considerando que eles são de cursos noturnos, geralmente, são trabalhadores durante o dia e que, à noite, muitas vezes estão cansados e desmotivados para aprender. 


\section{O “JOGO DAS QUATRO PISTAS CLIMÁTICAS” NO ENSINO MÉDIO}

Ao planejar atividades práticas em que os alunos sejam ativos no processo de aprender, consideramos o contexto em que vivem e aprendem, as atividades cotidianas que realizam, o nível de aprendizagem a que estão inseridos, neste caso o Ensino Médio e, a partir desses aspectos, relacionamos os conteúdos a serem trabalhados na Geografia. Sendo assim, no planejamento da atividade prática, o tema principal escolhido foi "os climas brasileiros", considerando também outros elementos envolvidos nas dinâmicas climáticas como: tempo meteorológico, fatores climáticos e elementos que influenciam no clima.

A situação de aprendizagem construída, a partir da proposta de oficina com jogos pedagógicos, constitui parte da formação docente dos acadêmicos do curso de Geografia (L) da Universidade de Passo Fundo (UPF), onde eles, nas disciplinas práticas do curso, são desafiados a pensar a aprendizagem da Geografia escolar em distintos espaços e são auxiliados a planejar atividades que possam ser realizadas com os alunos. Sendo assim, foi realizada uma atividade de oficina pedagógica com uma turma de $1^{\circ}$ ano do Ensino Médio noturno em uma escola pública estadual, localizada no espaço urbano do município de Passo Fundo/RS.

Para o desenvolvimento da oficina pretendeu-se idealizar e executar um jogo pedagógico sobre climatologia. Está atividade tinha como intuito: a) abordar os principais climas brasileiros e suas influências em cada região, dialogando com os alunos sobre as características dos climas de alguns estados e também sobre o tempo meteorológico, relacionando-os com a realidade dos seus lugares de vivência; b) identificar e diferenciar cada clima, através de um jogo pedagógico, considerando peculiaridades em distintos lugares; c) representar os climas brasileiros através de características referentes às suas dinâmicas.

Utilizou-se na construção destes conhecimentos, além do conceito de clima e tempo, a interpretação geográfica a partir dos conceitos de lugar e paisagem, aliando a isso a multiescalaridade dos fenômenos no espaço, através da escala de análise geográfica, realizando a análise geográfica no diálogo com os alunos ao longo das atividades desenvolvidas. Sendo assim, no processo de desenvolvimento da atividade prática procurou-se construir um trabalho coletivo com eles, para que houvesse interação, trabalho em equipe, participação e pensamento colaborativo, a partir da participação de todos, e com isso, o processo de aprendizagem fosse mais dinâmico, contribuindo para o desenvolvimento da capacidade cognitiva dos mesmos.

A turma de $1^{\circ}$ ano do Ensino Médio é composta por 20 alunos levando em conta a chamada dos professores, porém estavam presentes apenas 12 deles e, considerando o tamanho 
da turma, os materiais foram planejados da seguinte forma: a) num cartão de cartolina havia quatro frases de perguntas (impressas em folhas brancas A4), distinguindo como pistas sobre os climas e as outras dinâmicas climáticas, alguns tinham uma imagem ao verso, para ajudar nas respostas, e os alunos conseguiam observar; b) cada pista tinha uma pontuação diferente a primeira valia 20 pontos, a segunda 15 pontos, a terceira 10 pontos e a quarta 5 pontos; c) ao final de cada cartão com as pistas tinha a resposta, porém só o acadêmico conseguia ver, e ele fazia a leitura das pistas para os alunos. Foram utilizadas folhas A4 para a impressão das pistas para o jogo pedagógico, canetão para escrever a pontuação no quadro branco, e cartolina azul para confeccionar os 20 cartões contendo as perguntas que compunham a dinâmica da atividade (Figura 1).

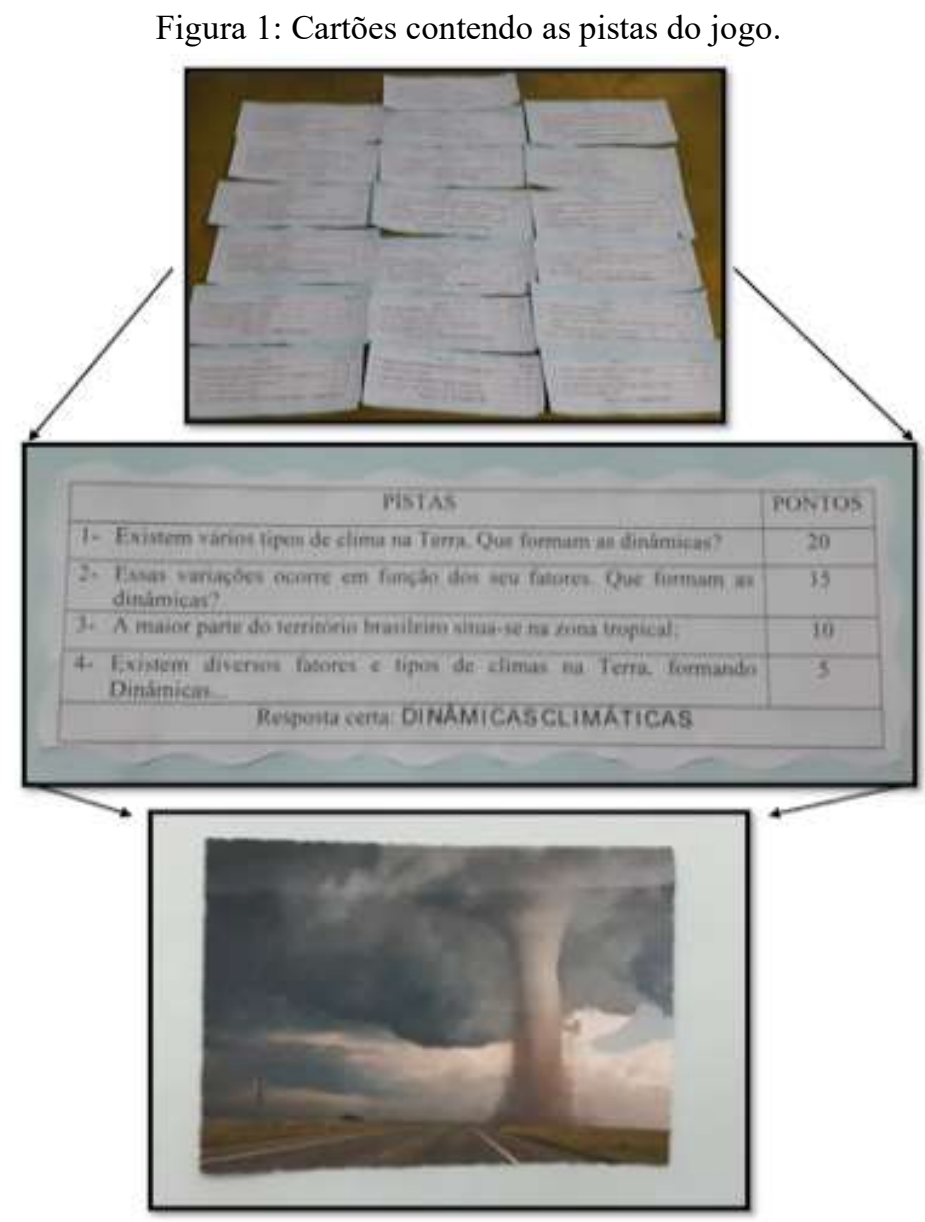

Fonte: Lisboa e Júnior (2018).

O Esquema 1 ilustra duas pistas que foram lidas para os alunos no momento da atividade prática. 
Esquema 1: Algumas pistas lidas no momento da atividade prática.

\begin{tabular}{|l|c|}
\hline \multicolumn{1}{|c|}{ PISTAS } & PONTOS \\
\hline $1-\quad$ Clima controlado pelas massas de ar tropicais e polares; & 20 \\
\hline $2-\quad$ Abrange parte da Região Sul e Sudeste; & 15 \\
\hline $3-\quad$ Baixas temperaturas no inverno; & 10 \\
\hline $4-\quad$ Já registrou temperaturas negativas; & 5 \\
\hline \multicolumn{2}{|c|}{ Resposta certa: CLIMA SUBTROPICAL ÚMIDO ou SUBTROPICAL } \\
\hline
\end{tabular}

\begin{tabular}{|c|c|}
\hline PISTAS & PONTOS \\
\hline 1- Fenômeno atmosférico composto por fortes ventos; & 20 \\
\hline 2- Também conhecido como temporal; & 15 \\
\hline 3- Acompanhado por trovoadas, relâmpagos, granizo e chuva; & 10 \\
\hline 4- Ocorre em todo o Planeta Terra; & 5 \\
\hline \multicolumn{2}{|c|}{ Resposta certa: TEMPESTADES } \\
\hline
\end{tabular}

Fonte: Lisboa (2018).

Foram utilizadas, ainda, cartolinas verdes para a divisão dos respectivos grupos (grupo "A" e grupo "B"), conforme ilustração na figura 2, e uma caixa para colocar as pistas, conforme a figura 3 .

O método construtivista perpassa essa atividade na medida em que se propõe uma relação mais dialógica, horizontal e problematizada entre professor e alunos. A proposta considera o professor como mediador do processo de aprendizagem e, a partir do planejamento que realiza, oferece possibilidades de interação dos alunos entre si e com os conhecimentos a produzir em sala de aula, ampliando espaços de diálogo, investigação e argumentação. Dessa forma desenvolveu-se a prática, considerando: a) distribuição de cartões com as identificações dos grupos; b) divisão em dois grupos, contendo 6 alunos em cada grupo; c) os 20 cartões foram utilizados como suporte para a dinâmica de interação, sendo que, a partir da leitura pelo acadêmico, os alunos dialogavam entre si e, por meio do conhecimento já construído sobre o conteúdo, respondiam as perguntas. 
Figuras 2 e 3: Cartões identificando os grupos em A e B (figura 2) e Caixa para colocar as pistas (figura 3).
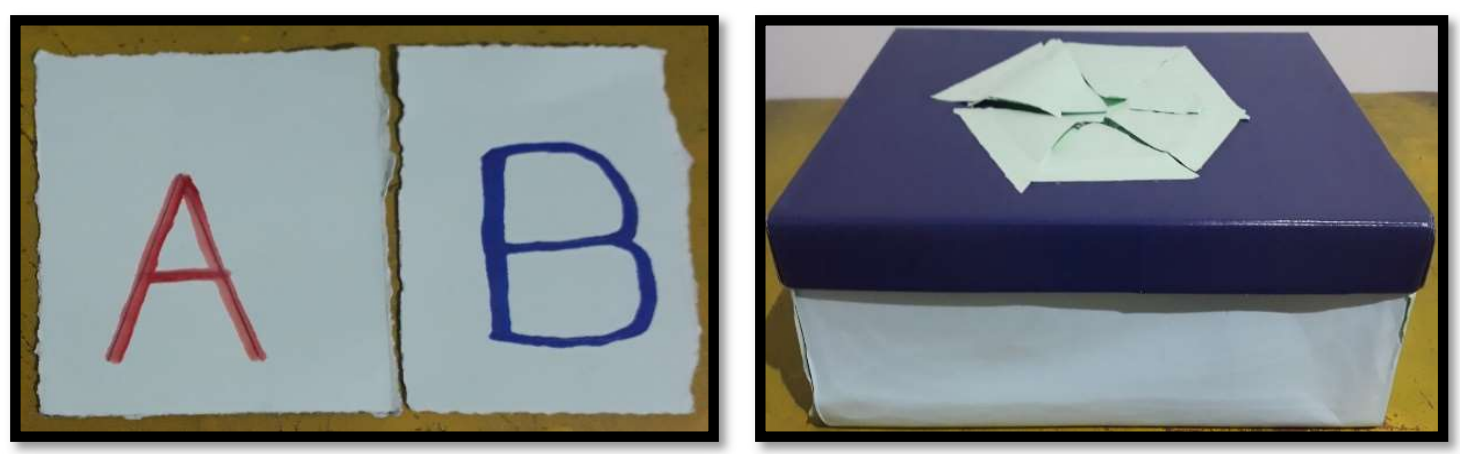

Fonte: Lisboa (2018).

Os materiais elaborados foram expostos no momento da aula e serviram para auxiliar em sua organização e desenvolvimento. Antes de desenvolver efetivamente o jogo pedagógico foi realizado inicialmente um diálogo introduzindo o tema em estudo, retomando aspectos que envolvem a climatologia, suas dinâmicas ao se tratar dos estudos do clima e sua relação com as nossas vidas.

A fim de retomar conhecimentos já construídos e compreender o que já conhecem sobre tempo e clima foi utilizado um texto contendo características básicas de cada clima brasileiro. O diálogo construído para relacionar conhecimento climatológico geográfico e os conhecimentos de cada aluno serviu para retomar alguns aspectos desse conhecimento e, ainda, para desenvolver a participação deles, projetando a etapa seguinte, de desenvolvimento do jogo. A conceituação dos climas foi construída com base no conhecimento em construção e utilizando livros didáticos disponíveis na escola.

No contato com os alunos e com os conceitos base inseridos na atividade, sejam eles os conceitos relacionados a tempo e clima, como aqueles considerados basilares na geografia (como lugar, paisagem, região...) constituem a construção de reflexões iniciais para pensar os climas e seus diferenciais e, assim, facilitar a compreensão dos alunos e debates sobre suas dúvidas desde o momento de leitura do texto inicial.

O Esquema 2 ilustra o texto utilizado para complementar a dinâmica que foi trabalhada em sala de aula.

Esquema 2: Texto referente à dinâmica.

\section{CLIMAS DO BRASIL:}

CLIMA EQUATORIAL: “Abrange a maior parte da região Norte. Caracteriza-se pelo predomínio de altas temperaturas e chuvas abundantes ao longo do ano" (SAMPAIO, p. 183, 2015). 
CLIMA SEMIÁRIDO: "Abrange a maior parte da Região Nordeste. Caracteriza-se pelo predomínio de altas temperaturas durante o ano todo" (SAMPAIO, p. 183, 2015).

CLIMA TROPICAL ATLÂNTICO: “Abrange parte do litoral das regiões Sudeste e Nordeste. Caracteriza-se pelo predomínio de altas temperaturas, com ligeiras quedas nos meses de inverno" (SAMPAIO, p. 183, 2015).

CLIMA SUBTROPICAL: "Abrange parte da Região Sul e Sudeste. Caracteriza-se pelo predomínio de baixas temperaturas no inverno e temperaturas quentes no verão" (SAMPAIO, p. $183,2015)$.

CLIMA TROPICAL: "Abrange grande parte do território brasileiro. Caracteriza-se pelo predomínio de verões mais quentes e chuvosos e invernos um pouco mais frios e secos" (SAMPAIO, p. 183, 2015).

Fonte: Lisboa (2018).

O "jogo das quatro pistas climáticas", proposto neste artigo, se baseia em um jogo denominado como "três pistas dos continentes", construído por SOUZA et. al. (2013)1 em que os autores se utilizam dessa metodologia ao trabalhar com alunos dos Anos Finais do Ensino Fundamental. Na proposta apresentada por eles, desenvolvem as seguintes etapas: a) confecção de cartões contendo as pistas; b) cada cartão com palavra-chave e a resposta no final; c) leitura para o primeiro grupo, caso não acertassem era feita a leitura para o outro grupo; d) a primeira pista valia 15 pontos, a segunda 10 pontos e a terceira 05 pontos; e) grupos de alunos eram divididos em dois.

O "Jogo das três pistas dos continentes" foi adaptado para o "Jogo das quatro pistas climáticas", apresentando como principais diferenças o tema e os assuntos trabalhados, a confecção de caixa para uso ao invés de envelopes, além de que são turmas e alunos distintos, sendo adaptadas também as propostas de organização e orientação das pistas para os mesmos, apresentando quatro pistas no jogo proposto.

\section{O DESENVOLVIMENTO DO “JOGO DAS QUATRO PISTAS CLIMÁTICAS” E AS APRENDIZAGENS A PARTIR DESSE RECURSO}

Ao planejar a atividade e desenvolvê-la com os alunos do $1^{\circ}$ ano do Ensino Médio noturno, além de considerar os aportes teóricos e conceituais da Geografia para abordar essa

\footnotetext{
${ }^{1}$ SOUZA, J. F. M.; SANTOS, L. J. dos; BETTIM, N. A.; OLIVEIRA, J. G. R.; Reflexões sobre a aplicação do "jogo das três pistas dos continentes" no $6^{\circ}$ ano do ensino fundamental via projeto PIBID-GEOGRAFIA/UENP. In: I Simpósio de Geografia e IX Semana de Geografia, 2013, Cornélio Procópio. Anais do I Simpósio de Geografia e IX Semana de Geografia. Cornélio Procópio: UENP, 2013.
} 
temática, foi necessário levar em conta a metodologia para o desenvolvimento da oficina na escola. Desse modo, ela foi organizada da seguinte forma:

$1^{\circ}$ Passo: Foi explicado o funcionamento da oficina e do tema abordado sobre os climas brasileiros, dialogando com os alunos;

$2^{\circ}$ Passo: Foram abordados os conceitos básicos sobre os climas brasileiros com a leitura do texto, sendo que cada aluno que se dispôs a contribuir, fez a leitura de um dos conceitos e estes foram debatidos;

$3^{\circ}$ Passo: Após a leitura de cada um dos conceitos foram explicadas as características, e após, localizados no mapa cada um dos climas brasileiros, propondo reflexões sobre as características e aspectos que os alunos já conheciam sobre esses climas. Neste momento, os alunos puderam refletir, dialogar e trocar ideias a partir do que conheciam sobre o assunto, através das suas realidades de vivência;

$4^{\circ}$ Passo: A turma foi dividida em dois grupos: A e B;

$5^{\circ}$ Passo: Foi dividido o quadro branco ao meio e escrito em cada parte grupo A e grupo $\mathrm{B}$;

$6^{\circ}$ Passo: Foram entregues para os grupos os dois cartões de cartolina verde com a identificação de cada um;

$7^{\circ}$ Passo: Foi apresentada a atividade prática que é denominada de "O jogo das quatro pistas climáticas" e explicado como seria o seu funcionamento que sobre a mesa, dentro de uma caixa, estavam 20 cartões contendo, cada qual, quatro pistas de um determinado clima brasileiro, além das características e de imagens sobre o tempo meteorológico.

$8^{\circ}$ Passo: Iniciou-se a atividade lendo a primeira pista, escolhida dentro da caixa um cartão e começando a falar a primeira pista para o grupo A. Se o grupo A acertasse, ganharia 20 pontos, mas se não acertasse, a vez passaria para o grupo B, seria lida a segunda pista, que valeria 15 pontos, e assim, sucessivamente. No entanto, se nenhum dos grupos conseguisse alcançar o objetivo de acertar, ambos não pontuariam.

No decorrer da atividade prática, houve um momento em que a mesma teve que ser interrompida, pois apesar dos alunos estarem participando e dialogando, interessados no grupo, havia muita dispersão e pouco raciocínio colaborativo e trocas de informações. Desse modo, os alunos foram instruídos a discutirem as respostas entre o grupo e quando este entrava em consenso, apenas um aluno falava a resposta em voz alta para os demais. A partir desse momento, percebeu-se que eles começaram a pensar juntos e trabalhar efetivamente em equipe. 
No percorrer do jogo, observou-se que o grupo A estava com dificuldades para interpretar e entender qual era a pista, pois havia comunicação, mas eles não sabiam do que se tratava porque era um conteúdo que eles tinham dúvida por não lembrarem. Nesse momento do jogo pedagógico a única coisa que era falada em sala de aula eram as pistas. Algumas tinham que ser repetidas e como regra do jogo, não era possível dar outras dicas ou sugestões, sendo que, ao final de cada acerto de pista era explicado o porquê de ser aquela resposta e qual eram suas influências, seus conceitos e suas características, novamente retomando aspectos deste conteúdo.

Já o grupo B pensava bastante sobre as pistas, participava de forma mais ativa e dava respostas mais corretas, acertando a grande maioria das perguntas, obtendo, assim, uma excelente pontuação. O processo de aprendizagem, a partir da investigação e da argumentação em grupo estava acontecendo, pois os alunos compreendiam e argumentavam sobre o que se tratava cada uma das pistas. Aos poucos, no decorrer da atividade, o grupo A também foi acertando algumas respostas, porém pontuou menos. Em alguns momentos, o grupo A chegou muito perto da resposta correta, o que trouxe outros elementos de debate para a construção do conhecimento sobre os climas e suas dinâmicas.

O tempo estipulado para cada grupo era de no máximo 2 minutos para pensar, refletir, interagir e compartilhar as respostas que consideravam certas. Ao final, o grupo B apresentou maior pontuação. No entanto, todos os participantes foram agraciados com um mimo de agradecimento pela participação na atividade.

É importante considerar que, no decorrer da atividade prática realizada na oficina, nem todos os cartões com as pistas foram retirados, uma vez que foram considerados complexos pelo acadêmico, assim, foram lidos 14 cartões com pistas e os alunos acertaram no máximo 7 cartões. Os cartões produzidos tratavam dos climas brasileiros, tempo meteorológico, elementos e fatores climáticos e, embora estivessem ilustrados com imagens retiradas da internet para facilitar o pensamento e a resposta final, mostraram-se muito complexos e inadequados para a faixa etária dos alunos, que era entre 16 a 20 anos.

Esse momento de reflexão durante a ação do acadêmico contribui para pensarmos que, durante as inserções em propostas práticas na escola, o mesmo tem a possibilidade de, ao desenvolver o seu planejamento, perceber e observar como ocorre a dinâmica da aprendizagem em sala de aula, se relacionar com os alunos, desenvolver seu pensamento para construir problematizações e argumentações que contribuam para ensinar e, se necessário, se reinventar e abandonar práticas inadequadas. 
Referente às pistas que foram lidas no momento da atividade prática, no primeiro instante do jogo nenhum dos grupos conseguiu responder corretamente, o que exigiu um momento da interrupção em que foi explicado sobre a necessidade de atenção e concentração para relacionar as pistas ao conhecimento construído, contribuindo para que o pensamento coletivo fluísse de forma mais abrangente. No decorrer das jogadas seguintes, os grupos chegaram as respostas corretas ou conseguindo argumentar de modo mais assertivo, trazendo elementos que contribuíram à construção de uma resposta coerente com os estudos realizados.

Ao avaliar a oficina, pode-se perceber alguns pontos negativos, como por exemplo, a falta de conhecimento básico por parte dos alunos sobre alguns dos aspectos dos assuntos climáticos propostos, afinal era um assunto que eles viram apenas nos Anos Finais do Ensino Fundamental, e como estavam no Ensino Médio, não recordavam muito. Além disso, no momento da atividade prática, mesmo tendo retomado esse conteúdo e procurado relacionar com seus conhecimentos e sua realidade, não houve tempo suficiente para aprofundamento sobre o assunto, o que envolve, portanto, mais tempo nesse processo de construção do conhecimento.

Entretanto, a explicação e os debates realizados no início da oficina não foram o bastante para os alunos conseguirem estabelecer algumas relações sobre esse conhecimento, retomando aspectos do assunto e desenvolvendo argumentação na atividade prática. Outro aspecto que pode ser mencionado é que isso é ainda mais difícil para eles que, em sua grande maioria são trabalhadores durante o dia e muitas vezes não conseguem prestar bastante atenção pelo cansaço e, também, não realizam leituras complementares sobre os assuntos em estudo.

Contudo, numa turma em que 12 alunos estavam presentes divididos em dois grupos, através do "Gráfico 1" abaixo pode-se perceber essa questão de não adquirir um conhecimento prévio.

Gráfico 1: Representação de alunos que sabiam e não sabiam do conteúdo.

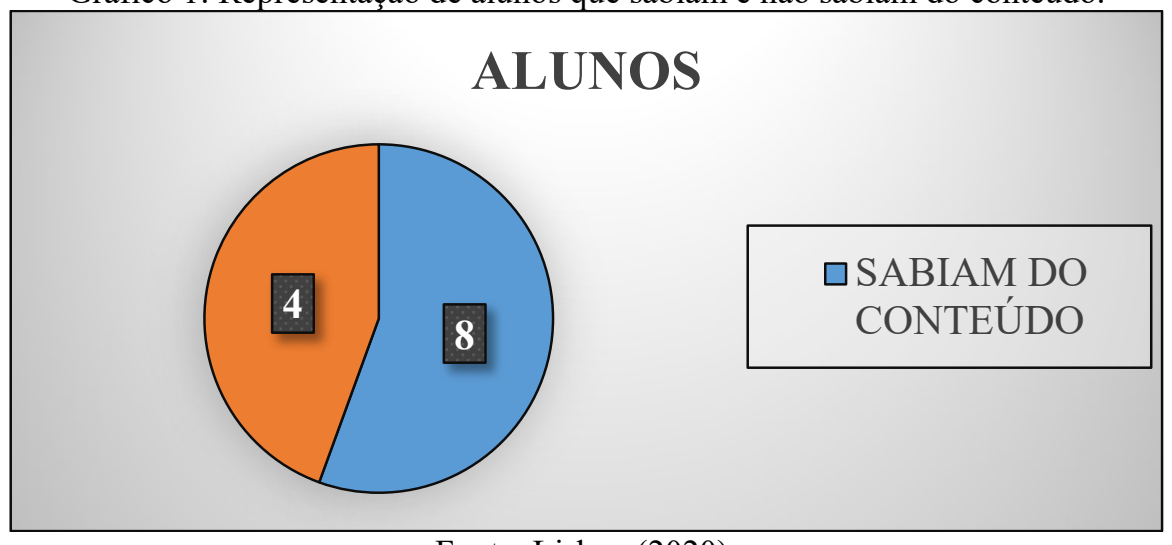

Fonte: Lisboa (2020). 
Esta constatação permitiu verificar que, para uma próxima atividade, é necessário construir antecipadamente o conhecimento com os alunos, através do estudo dos conceitos, de debates sobre os climas e suas características, de atividades de investigação e problematização a partir de sua realidade, em outros momentos anteriores, no intuito de tornar mais significativos os conhecimentos. Isso pode ser proposto uma aula antes do jogo e a partir de distintas estratégias que se adequem aos alunos, para ter mais tempo de explicar e dialogar com eles. Além disso, deve-se usar outros aportes teóricos sobre os conteúdos estudados para que, quando realizada a atividade prática, eles possuam um lastro de conhecimento que lhes permita relacionar de forma mais significativa as suas realidades e outros lugares do país e do mundo.

Outro aspecto a considerar a partir dessa atividade prática, é a necessidade de um conhecimento muito amplo do assunto, além do conhecimento de temas específicos. Segundo Dantas et. al. (2016, p. 1379):

\begin{abstract}
No ensino de Geografia, o conteúdo de climatologia precisa não só da utilização de metodologias, mas da preparação adequada do professor. Pensando na própria eficácia da prática educativa valorativa ao professor e ao educando, necessita-se de um processo de ensino-aprendizagem que traga de fato correlações da realidade com o saber científico.
\end{abstract}

Isso porque os alunos têm distintos conhecimentos sobre o mundo, sobre lugares, mas nem sempre conseguem relacioná-los entre si. E o acadêmico, enquanto professor em formação, também está se construindo, o que exige, em muitos momentos, a utilização de textos, de referenciais de outros autores, de propostas de livros didáticos, além de desenvolver sua criatividade, para conseguir aprofundar os conhecimentos e não ficar apenas na superficialidade da identificação dos climas e de suas características. Por isso, o espaço para o debate e para a elaboração de oficinas nas escolas se faz necessário e essencial no decorrer da graduação, uma vez que contribui também para a construção do conhecimento do acadêmico.

Nesse sentido, Copatti (2014, p. 175) enfatiza que:

\begin{abstract}
A aprendizagem em Geografia se dá nas experiências, nos diálogos, nas análises realizadas, nas trocas entre professor, aluno e entre estes no exercício da cooperação e da reflexão em relação a diversos assuntos, estes que aproximam a ciência geográfica e o cotidiano do ser humano vivendo em sociedade.
\end{abstract}

Novamente de acordo com Copatti (2014), a verificação da aprendizagem deve ser um processo continuado, realizado em diferentes momentos e de formas variadas, a partir das 
vivências e das construções realizadas no ambiente escolar e de sala de aula, considerando tanto o desenvolvimento dos alunos quanto o trabalho do professor que o planeja.

Como ponto positivo, cabe destacar que apesar das dificuldades apresentadas pelos alunos, o conhecimento foi adquirido tornando a prática como possibilidade de diálogo em grupo, de investigação, de resolução de desafios e problemas. Mas, essa proposta prática precisa sempre de um embasamento teórico e de momentos de estudo que envolvam concentração, debate sobre diferentes realidades e sobre aquilo que os alunos possuem de conhecimento do mundo. Dessa forma, entende-se que o jogo pedagógico, de alguma forma, contribuiu ao processo de aprendizagem deles ao proporcionar a interação com os demais colegas, o trabalho em equipe a construção de argumentação e a retomada de conhecimentos básicos sobre os climas e suas características.

No Gráfico 2 pode-se perceber a proporção de alunos que gostaram e os que não gostaram da atividade prática.

Gráfico 2: Representação de alunos que gostaram e os que não gostaram da atividade prática.

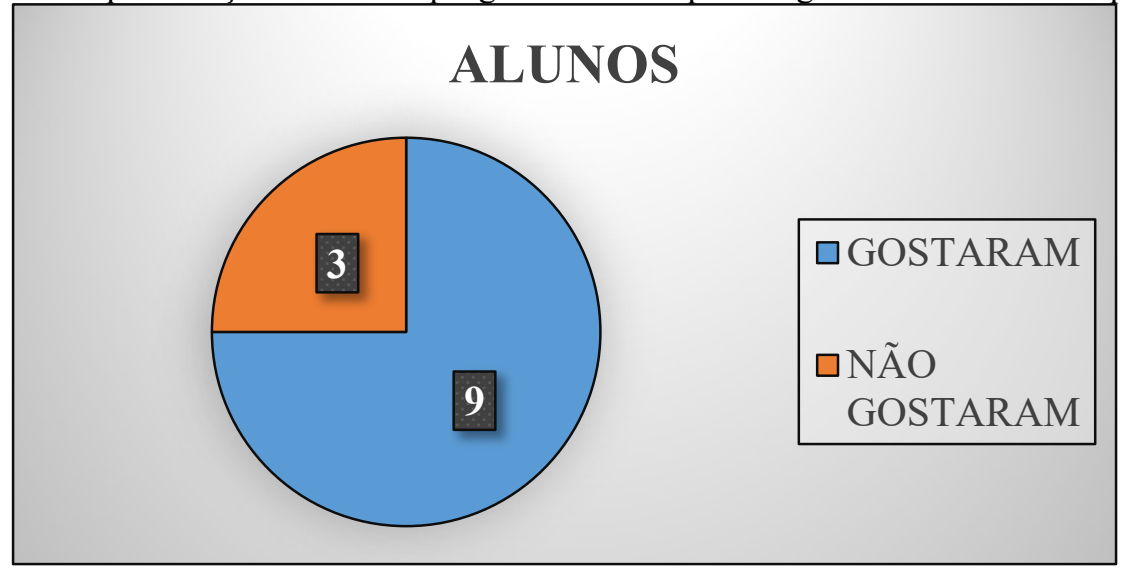

Fonte: Lisboa (2020).

Destaca-se, que os alunos que comentaram não gostar da atividade explicam que não tinham conhecimento suficiente do conteúdo trabalhado, já os que gostaram demonstraram interesse no conteúdo e conseguiram ampliar conhecimentos. Para todos entende-se que foi possível retomar o conteúdo e estabelecer maior contato entre conteúdo, interação com os colegas e pensar a realidade. Sendo assim, é importante salientar que não houve apenas interação entre os grupos, mas também houve a interação entre os alunos e o acadêmico que desenvolveu a proposta, no intuito de construir outras possibilidades de aprendizagem.

Também é uma oportunidade de aproximação do acadêmico com a Educação Básica e de testar conhecimentos apreendidos na universidade na relação com a escola, tornando-as cada vez mais próximas uma da outra. Pode-se constatar, com isso, que a construção do processo de 
ensino e aprendizagem, ao ser realizado de modo divertido e dialógico, pode contribuir para o conhecimento dos conteúdos de Geografia, a partir de situações já conhecidas e de outras construídas na interação com os colegas em sala de aula.

\section{CONSIDERAÇÕES FINAIS}

Neste artigo buscou-se refletir sobre a utilização do jogo pedagógico como possibilidade metodológica no Ensino de Geografia no Ensino Médio, relacionando aspectos teóricos e práticos na construção de conhecimentos que sejam significativos aos alunos. Dessa forma, entendemos que, para trabalhar determinados conteúdos e temas em Geografia se faz necessário definir conceitos basilares que contribuam para realizar análises, muito mais do que trabalhar apenas a partir da explicação e da atividade prática.

Definimos os conceitos de lugar e de paisagem, com o intuito de facilitar a relação da aprendizagem com os conceitos e elementos específicos sobre o clima, e com os ambientes que os alunos percebem e vivenciam na relação do cotidiano com o espaço geográfico. Sendo assim, a oficina contou com uma etapa inicial teórica e dialogada, baseada no aporte geográfico, e após, uma atividade prática denominada "o jogo das quatro pistas climáticas”, a qual visou contribuir para a construção do conhecimento dos alunos.

Essa proposta foi pensada para ser desenvolvida a partir de uma dinâmica de trabalho em equipe que gerasse melhores resultados, fazendo com que os alunos desenvolvessem habilidades que possam ser usadas, não apenas no componente curricular Geografia, mas em todos que compõem o currículo escolar. E, ainda, percebendo que aprender Geografia pode ir além das propostas tradicionais de memorização e transmissão de conteúdos sem sentido para a vida.

A partir do desenvolvimento da oficina de jogo pedagógico pudemos constatar que esta atividade contribui para a construção do conhecimento dos alunos, mas possui limitações quando não realizada de acordo com um planejamento mais amplo e aprofundado, o que não foi possível de ser realizado anteriormente. Tornou-se possível, também, perceber que a maioria dos alunos não tinha um conhecimento aprofundado sobre o conteúdo. Mesmo assim, percebeuse que o jogo pedagógico contribui para retomar conhecimentos sobre o assunto, para estabelecer maior diálogo entre professor e alunos e entre eles, enquanto colegas, relacionando o que foi explicado no começo da atividade e o que aprenderam nos Anos Finais do Ensino Fundamental, estabelecendo também relações com a realidade. 
Além disso, a atividade contribuiu para a ampliação do conhecimento do acadêmico em processo de formação como professor, pois ao planejar essa oficina, construiu aportes para as explicações e diálogos propostos, relacionando dimensões do conhecimento científico e do conhecimento escolar desenvolvido com os alunos. Constitui, portanto, uma etapa importante na formação do acadêmico por possibilitar as primeiras inserções no ambiente da sala de aula e no desenvolvimento de suas propostas de atuação docente.

Portanto, considera-se que as propostas que aliam teoria e prática em todo o seu planejamento e desenvolvimento demonstram, para além do cuidado com a aprendizagem, um maior contato entre a universidade e a escola. E que a inserção do acadêmico em oficinas diretamente nas escolas estabelece o diálogo com o conhecimento científico e escolar e dá maior visibilidade à ciência geográfica.

\section{REFERÊNCIAS}

CALLAI, Helena. Aprendendo a ler o mundo: a geografia nos anos iniciais do ensino fundamental. Cad. Cedes, Campinas, v. 25, n. 66, p. 227-247, maio/ago. 2005.

COPATTI, Carina. Avaliação escolar em geografia: contribuições da educação estética nesse processo. Revista Olh@res. UNIFESP.v.2, n. 1.pp. 168-193.

DANTAS, Sulivan. O Ensino de Climatologia Geográfica: uma abordagem de intervenção sobre os conceitos básicos de Clima e Tempo. REGNE, v. 2, número especial, 2016.

ENGEL, Guido Irineu. Pesquisa-ação. Educar, Curitiba, v. 16, n. 16, p. 181-191, 2000. Editora da UFPR.

GEOGRAFIA; Ensino de geografia: Jogo das quatro pistas. Disponível em: $<$ www.ensinodegeografiauenp.blogspot.com.br>. Acesso em: 18 ago. 2018.

JÚNIOR, Isaías. Tornados: Uma das forças mais destruidoras da natureza. Disponível em: $<$ https://climatologiageografica.com/tornados-uma-das-forcas-mais-destruidoras-danatureza.com.br> Acesso em: 15 out. 2018.

LISBOA, Yan Castro; JORGE, Márcia da Silva. O ensino de geografia e suas práticas pedagógicas: Atividade lúdica desenvolvida na educação básica. In: IV SEMINÁRIO DO PROGRAMA DE PÓS-GRADUAÇÃO EM GEOGRAFIA DA UNIVERSIDADE FEDERAL DE PELOTAS, 4., 2017, Pelotas. Anais do IV Seminário do Programa de Pós-Graduação em Geografia da Universidade Federal de Pelotas. Adriano Luís Heck Simon, Débora Pinto Martins, Maurício Meurer (Orgs.). Pelotas: UFPel, 2017. p. 124-129.

MENDONÇA, Francisco, OLIVERIA, Inês Moresco Danni. Climatologia-Noções básicas e climas do Brasil. São Paulo: Oficina de Textos, 2007. p. 11-25. 
NETO, F. O. L.; BARBOSA, M. E. S.; O ensino de geografia na educação básica: Uma análise da relação entre a formação do docente e sua atuação na Geografia escolar. Revista de Estudos Geoeducacionais. Ceará, v. 1, n. 2, p. 160-179, jul./dez. 2010.

SAMPAIO, Fernando dos Santos; Geografia, $6^{\circ}$ ano: Anos finais do Ensino Fundamental. 2.ed. São Paulo: Edições SM, 2015.

SAMPAIO, Fernando dos Santos; SUCENA, Ivone Silveira; Geografia: Ser protagonista. 2.ed. São Paulo: Edições SM, 2010.

SANTOS, Milton. Metamorfoses do espaço habitado: fundamentos Teórico e metodológico da geografia. São Paulo: Hucitec, 1988.

SAWCZUK, K. I. L.; MOURA, J. D. P.; Jogos pedagógicos para o ensino da geografia. In: O professor pde e os desafios da escola pública paranaense. Ângela Maria Piovezan Batista, Jane Célia Volpato, Maria Regina Bach (Orgs.). Paraná: Secretária da educação, 2012. p. 1-19

SOUZA, J. F. M.; SANTOS, L. J. dos; BETTIM, N. A.; OLIVEIRA, J. G. R.; Reflexões sobre a aplicação do "jogo das três pistas dos continentes" no $6^{\circ}$ ano do ensino fundamental via projeto PIBID-GEOGRAFIA/UENP. In: I Simpósio de Geografia e IX Semana de Geografia, 2013, Cornélio Procópio. Anais do I Simpósio de Geografia e IX Semana de Geografia. Cornélio Procópio: UENP, 2013.

TOPOLSKI, Chilavet; LISBOA, Karina de Lírio; PESSETTI, Mateus; ROSA, Paula Rodrigues da; LISBOA, Yan Castro; BITENCOURT, Luciane Rodrigues de; JORGE, Márcia da Silva. A utilização da gincana geográfica como recurso metodológico no processo ensinoaprendizagem. In: Saberes e experiências em construção: a importância do PIBID. Luiz Marcelo Darroz, Maria de Fátima Baptista Betencourt, Patrícia da Silva Valério (Orgs.). Curitiba: CRV, 2018. p. 613-625.

TRIPP, David. Pesquisa-ação: uma introdução metodológica. Educação e Pesquisa, São Paulo, v. 31, n. 3, p. 443-466, set./dez. 2005.

VEDOVATE, Fernando Carlo; Projeto Araribá: Geografia. 3. ed. São Paulo: Moderna, 2010. 